\title{
ENSAYO DE DEFINICIÓN ARQUEOLÓGICA DE LAS ETNIAS PRERROMANAS DE ANDALUCÍA
}

\author{
TOWARDS AN ARCHAEOLOGICAL DEFINITION OF \\ ANDALUSIAN PRE-ROMAN ETHNIC GROUPS
}

por

\author{
RAQUEL LACALLE RODRÍGUEZ
}

RESUMEN Hemos realizado un intento de delimitación de las fronteras étnicas del período ibérico a través del análisis de diversos elementos culturales pertenecientes a las poblaciones que habitaron Andalucía durante esta etapa. El estudio de la distribución de las esculturas de leones ha sido un punto de partida que nos ha permitido delimitar ciertas áreas que hemos definido como territorios étnicos. Los datos proporcionados por las fuentes escritas nos han llevado a correlacionar el área de dispersión de la estatuaria de leones en Andalucía con la etnia oretana.

\begin{abstract}
We have tried to delimit the ethnic boundaries of the Iberic period by analyzing different cultural elements pertinent to the populations that inhabited Andalusia during this period. The study on the distribution of the lion sculptures is the starting point which allows us to define certain areas as ethnic territories. We have correlated the area of dispersion of the lion sculptures with the "oretano" ethnic group, according to the data gathered from written sources.
\end{abstract}

\section{INTRODUCCIÓN}

Se ha intentado identificar, de entre todos los aspectos que conforman la cultura de los pueblos, aquellos que por sus características especiales pueden más claramente ser considerados como identificadores de una etnia. Según lo señalado por diversos autores, la organización socioeconómica y política, la forma en que ésta se refleja a través de la superestructura, las estrategias de ocupación de un territorio, las directrices principales de su economía, la lengua, las fronteras geográficas, son aspectos que permiten una mejor diferenciación y delimitación de los pueblos, concretando y matizando mucho más que otros elementos de la cultura material (Escacena 1992; Burillo 1993; Chapa 1980: 11; Almagro-Gorbea 1982). 
Al enfrentarnos con esta problemática, hemos creído necesario tratar de establecer qué elementos arqueológicos, pertenecientes a las sociedades peninsulares, pueden resultar adecuados a la hora de diferenciar a las distintas etnias que poblaron Andalucía durante la etapa ibérica.

El estudio de la estatuaria animalística ibérica se convierte en un inestimable instrumento de trabajo para este cometido. La estatuaria zoomorfa constituye uno de los elementos más relevantes y característicos de las sociedades prerromanas peninsulares, afectadas e influidas por el advenimiento de corrientes culturales foráneas. El surgimiento del fenómeno de la estatuaria monumental a partir del $\mathrm{s}$. VI a. C. es el producto del reforzamiento y la concentración del poder en determinados grupos sociales, necesitados de símbolos de poder que les permitan ratificar y exaltar su posición dentro de sus respectivas comunidades. Este tipo de manifestación artística e ideológica refleja el profundo cambio económico y social gestado en estas comunidades, siendo su presencia indicativa de los procesos de aculturación producidos sobre los diversos sustratos indígenas en el marco de una amplia red de intercambios comerciales.

La observación de su distribución permite inferir la existencia de áreas con importantes densidades escultóricas que contrastan fuertemente con otras zonas que presentan marcados vacíos. Este hecho nos ha llevado a plantear la posibilidad de que las áreas con presencia de estatuaria puedan definirse como territorios pertenecientes a colectivos conocidos a través de las fuentes escritas.

Sin duda, el uso de este tipo de esculturas por parte de ciertas sociedades debió poseer un significado especial para aquellos grupos, ya que se trata de elementos dotados de una significación ideológica y, a la vez, política. La presencia de esta estatuaria implica la práctica de unos cultos y de una ideología común por parte de los grupos que hicieron levantar estos monumentos, configurando un espacio que posee unas determinadas características a nivel étnico y político. Ciertos grupos consiguen de este modo establecer y subrayar sus vínculos mediante ciertos rasgos unitarios, a la vez que logran marcar sus diferencias con respecto a aquellos otros colectivos que carecen de ellos. Desde esta perspectiva, no podemos considerar estos monumentos como meros objetos materiales que ofrecen distribuciones aleatorias, sino como elementos insertos en sistemas ideológicos específicos que adquieren un significado en un contexto étnico determinado pero que asimismo carecen de él entre otros grupos, adquiriendo así un pleno sentido su distribución en el espacio.

De entre el amplio repertorio zoomorfo reflejado en el mundo escultórico ibérico, nos hemos centrado especialmente en la figura del león, al interesarnos especialmente su evolución cronológica y su dispersión espacial en tierras andaluzas. El análisis de su distribución nos permitirá delimitar algunas zonas caracterizadas por una importante concentración escultórica que contrastan acentuadamente con otros sectores que ofrecen un manifiesto vacío. Es precisamente este juego de contrastes el que nos puede brindar la oportunidad de identificar posibles territorios, basándonos en la presencia o ausencia de leones.

Pretendemos que el análisis de la distribución de la estatuaria de leones nos sirva como punto de partida para la identificación de posibles territorios étnicos en Andalucía. El acceso a las fuentes escritas lo consideraremos imprescindible para tratar de corroborar si realmente existen correlaciones entre estas distribuciones y la información que nos proporcionan los textos antiguos. Asimismo, la introducción de otros elementos de juicio nos permitirá afianzar las hipótesis de trabajo que surjan a lo largo de este trabajo.

\section{ANÁLISIS DE LAS DISTRIBUCIONES}

Las representaciones de leones resultan muy indicadas para el estudio de la configuración de territorios en Andalucía debido a su evolución diacrónica. Si se observa la secuencia temporal de su dispersión, a partir de los estudios realizados por Teresa Chapa, se aprecia la delimitación de dos grandes "áreas": el grupo antiguo, ubicado en la zona del Alto Guadalquivir, y el grupo más reciente, a partir del s. III a. C. que conforma un nuevo núcleo en torno al Bajo Guadalquivir (fig. 1 y 2) (Chapa 1985). 
El foco del Alto Guadalquivir ocupa la margen izquierda del río, zona de valles amplios, apta para la explotación agrícola, dejando despejada la otra orilla, de carácter más montañoso. Sólo se localiza alguna escultura aislada en la margen derecha del Guadalquivir a partir de Cástulo. Si acudimos a los textos antiguos, Estrabón (III, 2, 3) menciona que el Guadalquivir dejaba de ser navegable precisamente a partir de la mencionada ciudad.

De la observación de esta mancha escultórica parece deducirse que los puntos aislados correspondientes a Cástulo y alguna que otra localización se hallan vinculados con los que con abundancia se concentran en la margen opuesta del río. Estas localizaciones muy bien podrían configurar un territorio político y étnico. Desde este punto de vista, la posición de Cástulo vendría dada por su situación estratégica de enlace con la ruta terrestre hacia el Mediterráneo, ubicándose justo donde Estrabón menciona que el río deja de ser navegable. El territorio se conformaría con una clara intencionalidad económica, el control de la ruta fluvial, así como la explotación agrícola del fértil valle del Guadalquivir. Sería un área con una delimitación geográfica muy propicia, al norte el Guadalquivir y por el sureste el sistema montañoso Subbético.

Todos estos datos inducen a pensar que esta zona podría corresponderse con un territorio, conteniendo los condicionantes propicios para serlo, entre ellos los geográficos. A su vez, la estatuaria dejaría traslucir una homogeneidad organizativa en la configuración del espacio político de esta zona.

El otro foco es el que surge en momentos posteriores, ya avanzados, a partir del s. III a. C., conformando un nuevo núcleo en el Bajo Guadalquivir. Durante estas fechas se mantiene vigente el grupo del Alto Guadalquivir, si bien con una menor densidad que en momentos anteriores. Los leones de época reciente se han relacionado con la llegada de Roma a la Península Ibérica (Chapa 1985: 148). No obstante, las escasas áreas ocupadas por este tipo de estatuaria, coincidentes con el foco antiguo de leones del Alto Guadalquivir y su área vecina, el Bajo Guadalquivir, pueden hacer pensar que el sustrato indígena que levantaba estos monumentos antes de la llegada de las legiones romanas pueda jugar algún papel en la nueva manifestación artística. En cualquier caso, el grupo reciente de leones forma un nuevo foco de concentración escultórica en el Bajo Guadalquivir, que puede poseer alguna implicación étnica o territorial que explique esta distribución confinada en el espacio. De nuevo, la estatuaria va a mostrar su predilección por las zonas de valle, contrastando con el fuerte vacío que presenta la zona montañosa de la margen derecha del río.

Es necesario resaltar la "extraña" ausencia de este tipo de esculturas en el Bajo Guadalquivir durante el período antiguo, si se mantiene la propuesta de situar el foco originario de la estatuaria monumental en este área. Si se pretende ver el origen de la estatuaria ibérica y de los motivos iconográficos en el período orientalizante en la zona del suroeste (Chapa 1985: 266), es inexplicable la ausencia de un foco escultórico en este sector. Por el contrario, por estas fechas las densidades escultóricas son fuertes tanto en la zona de Levante como en la del Alto Guadalquivir (fig. 1), lo que deja entrever claramente que la vía de penetración de esta corriente no es el suroeste, sino el Levante, continuando a través del curso del Guadalquivir.

Es destacable que aquellas áreas más vinculadas con el comercio fenicio rechazan este tipo de manifestaciones, mientras que son las rutas que mantienen una más estrecha relación con el comercio griego las que van a decantarse por su uso.

El mapa de Andalucía ofrece un extenso vacío, frente a los reducidos sectores ocupados por estos monumentos. El contraste escultura/no escultura, nos podría permitir identificar las fronteras que separan a dos grupos distintos. El área montañosa al norte del Guadalquivir se muestra impermeable al fenómeno de la estaturaria. Las concentraciones tienen lugar en las zonas de valle, al sur del Guadalquivir. Hallazgos recientes de esculturas de leones (Escacena, com. oral), no incluidos en los trabajos de T. Chapa (1980; 1985; 1986), señalan su prolongación hacia la margen derecha del río en su desembocadura, dentro del área del valle, en la provincia de Huelva. A su vez, todo el sector más meridional a partir de la costa destaca por la ausencia de esculturas, contrastando con las áreas próximas al Guadalquivir. Convendría introducir nuevos elementos que permitan matizar dentro de este enorme vacío material que rodea a las áreas con presencia escultórica. 
Almagro-Gorbea identificó el grupo bastetano a través de la dispersión de las tumbas de cámara y cajas funerarias, a las que se podría añadir las esculturas de diosas entronizadas (Almagro-Gorbea 1982; Montenegro y otros 1989: 324) (fig. 5). Tendrían por centro su capitalidad, Basti (Baza, Granada), y ocuparían la zona montañosa del Subbético y del interior de Granada. Los bastetanos, caracterizados por ofrecer estas distribuciones, se diferenciarían del grupo vecino del Alto Guadalquivir que ignoraría los citados elementos y se definiría por el uso de las esculturas de leones, a las que podríamos añadir las representaciones de toros que ocupan idéntica extensión (fig. 3) (Chapa 1985).

Existirían algunas zonas neutras, caracterizadas por ofrecer materiales adjudicables a cualquiera de los dos mencionados grupos (La Guardia, Cástulo). Hemos de ver aquí el producto de un proceso de movilidad de estas comunidades, sujetas a una expansibilidad. A la hora de intentar una demarcación de fronteras deberíamos tener siempre en consideración la variabilidad a la que han estado sujetos los límites territoriales (Escacena 1992: 322) de estos colectivos, adjudicando a los teóricos límites fronterizos una cierta flexibilidad.

Las cámaras funerarias y diosas entronizadas permitirían distinguir al grupo bastetano. A partir de este área cultural se dibujaría otro sector que esquivaría la presencia de este material; sería la zona costera correspondiente a los asentamientos fenicios, desde Cádiz hasta Murcia.

El análisis de las distribuciones nos ha llevado a la caracterización de sectores definidos por distintos comportamientos a nivel cultural en la región andaluza que mantendremos como hipótesis de trabajo y que podrían traducirse en territorios étnicos si las fuentes escritas les dotan de esta atribución.

\section{FUENTES ESCRITAS}

El estudio de las fuentes escritas antiguas ofrece la posibilidad de confrontar los testimonios aportados por la arqueología con lo que los autores clásicos nos transmitieron. En las siguientes líneas trataremos de ubicar a las diversas etnias conocidas a través de los textos, correlacionándolas con las hipótesis de trabajo obtenidas del estudio de distribuciones del material arqueológico.

Las fuentes mencionan a las siguientes etnias como habitantes del solar andaluz.

\section{1. Turdetanos y túrdulos}

Los autores clásicos mantuvieron opiniones contradictorias sobre la diferenciación étnica existente entre estas poblaciones. Las fuentes nos muestran un panorama confuso, puesto que los términos son manejados con bastante libertad por los autores. Algunos utilizan el término turdetano o el de túrdulo indistintamente, como si fueran sinónimos; otros establecen distinciones, atribuyéndolos a etnias diferentes: los turdetanos, sucesores de los antiguos tartesios, y los túrdulos, ubicados al norte de los anteriores (Lomas y otros 1980:151). En otras ocasiones, los términos turdetano y túrdulo poseen un matiz más ligado a lo cultural, vinculado a la expansión de la cultura tartésica en su período de máximo apogeo (Arteaga 1977: 306).

Así Estrabón nos dice (III, 1, 6) ${ }^{1}$ :

"Dicha región se llama Baitiké, del nombre del río, y Tourdetanía, del nombre del pueblo que la habita; a estos habitantes llámeseles tourdetanoí y tourdoúloi, que unos creen son los mismos; mas, según otros, dos pueblos distintos. Polýbios está entre estos últimos, pues dice que los tourdetanoí tenían como vecinos por su Norte a

1. Traducción de A. García y Bellido (1993). Todos los textos de Estrabón mencionados en este trabajo han sido extraídos del citado libro. 
los tourdoúloi. Hoy día no se aprecia ninguna diferencia entre ambos pueblos... Dicha comarca, sita al lado de acá del Ánas, se extiende hacia el este hasta la Oretanía, y por el Sur hasta la costa comprendida entre las bocas del Ánas y las Columnas".

En otro pasaje (III, 2, 11):

\begin{abstract}
"Parece ser que los antiguos llamaron al Baítis Tartessós, y a Gádeira y sus islas vecinas, Erýtheia... Y como el río tiene dos desembocaduras, dícese también que la ciudad de Tartessós, homónima del río, estuvo edificada antiguamente en la tierra sita entre ambas, siendo llamada esta región Tartessís, la que ahora habitan los tourdoúloi".
\end{abstract}

Estos dos fragmentos parecen contener ciertas contradicciones. En el primero de ellos (III, 1,6) se identifica a turdetanos y túrdulos y se los ubica a partir del Guadiana, teniendo sus límites por el sur desde el Guadiana hasta las Columnas. Si bien, en el segundo pasaje (III, 2,11) constriñe estas fronteras. En este segundo caso Estrabón emplea el término túrdulo como equivalente a turdetano, propio de los herederos de los antiguos tartesios, y ubica la región dentro de la doble desembocadura del río, fácilmente identificable con la zona comprendida entre las desembocaduras del Guadalquivir y el Guadalete. Estos últimos datos vendrían a coincidir con el área por la que se expandirán las esculturas a partir del período reciente.

Creemos que, aunque Estrabón se muestra partidario de la no distinción entre las dos poblaciones, existen ciertas referencias en sus propios textos, como las ya aludidas, que nos están hablando de dos realidades distintas.

Podríamos admitir en este caso el juicio de Polibio que situaba a los túrdulos al norte de los turdetanos, zona de vacío escultórico. La zona de sierra al norte del Guadalquivir, con una diferente configuración geográfica, podría ser el área ocupada por los túrdulos, distinguiéndose así de los agricultores del valle, los turdetanos.

Comenta al respecto Estrabón (III, 2, 15): “...los tourdetanoí, sobre todo los que viven en las riberas del Baítis, han adquirido enteramente la manera de vivir de los rhomaíoi, hasta el punto de haber olvidado su idioma propio".

El autor hace una apreciación y menciona a los tourdetanoí que viven en las riberas del Guadalquivir como más afines a la cultura romana. ¿Pudo existir una base de diferenciación entre los grupos ubicados a ambas márgenes del río, con diferentes modos de vida por estar sometidos a diferentes condicionantes geográficos que, aunque emparentados, sobre todo, en el período de máximo esplendor de Tartessos, haya podido traducirse en alguna distinción de la que se harían eco las fuentes? Podríamos diferenciar a los grupos que viven en el valle del Guadalquivir, ocupando principalmente la margen izquierda, los que utilizan las esculturas monumentales, de los que se sitúan en la margen derecha del río en la zona montañosa, grupos de tradición pastoril que carecen de estatuaria monumental.

Añade Estrabón (III, 2, 15): “... Las ciudades ahora colonizadas como Paxaugoústa, entre los keltikoí; Augoústa Emérita, entre los tourdoúloi...".

Algunos autores recogen en los textos una expansión de los grupos túrdulos por la zona límite entre la Bética y la Lusitania (Mela III, 8; Plinio IV, 113) ${ }^{2}$. Según las fuentes estos tourdoúloi habían llegado a estas tierras en una campaña de célticos y túrdulos del Anas hacia el Léthes (Limia), el río del olvido, donde se negaron a continuar por temor a perder el recuerdo de sus orígenes (Estr. III, 3, 5).

Cuando se hace referencia a la expansión de estos pueblos siempre se les denomina túrdulos y nunca se les confunde con turdetanos.

2. Las citas de Plinio y Mela han sido tomadas de A. García y Bellido (1987).

ISSN: 1133-4525 ISSN-e: 2255-3924

SPAL 6 (1997)

http://dx.doi.org/10.12795/spal.1997.i6.10 
Estrabón (III, 2, 3) nos describe una Beturia y sitúa sus secas llanuras bordeando el curso del Ánas (Rodríguez 1993). Plinio localiza la Beturia entre el Betis y el Ánas y la divide en dos zonas que pertenecen a otros tantos pueblos: los célticos y los túrdulos (III, 3, 13). Este fragmento serviría de punto de apoyo para considerar la ubicación de los túrdulos al norte del Guadalquivir.

Plinio sitúa a los túrdulos de la Beturia en el convento cordubense y recoge las siguientes ciudades: Arsa, Mellaria (Fuente Ovejuna), Mirobriga (Capilla), Regina (Reina), Sosintigi y Sisapo (Almadén) (III, 3, 13-14).

Estos datos pueden dar una idea sobre la región ocupada por los túrdulos, al norte del Guadalquivir.

No incluimos los datos proporcionados por Ptolomeo $^{3}$ (autor de época bastante tardía), ya que creemos bastante confuso el concepto de turdetano y túrdulo manejado por dicho autor. Si se observa sobre el mapa las ciudades citadas por él como túrdulas y turdetanas, hace pensar que Ptolomeo debió manejar una mezcolanza de datos procedentes de diversas fuentes, muchas de ellas referentes al período orientalizante, que no es el que aquí nos interesa.

Los datos suministrados por los textos, contrastados con el mapa de distribuciones, nos hacen mantener una distinción entre turdetanos y túrdulos, muy probablemente vinculada a diferencias en sus modos de vida, probablemente un carácter más pastoril y nómada de los segundos que explicaría en parte sus migraciones, recogidas por las fuentes, aunque estas diferencias debieron ser casi nulas en determinados períodos de la Protohistoria, sobre todo en el Orientalizante, por su vinculación a través de la ruta del estaño. Así pues, situaríamos a los turdetanos en la zona del valle del Guadalquivir hasta el Guadalete, la que debió ser su zona nuclear, mientras que los túrdulos quedarían ubicados en la zona montañosa, entre el Guadalquivir y el Guadiana.

\section{2. Libio-fenicios o bástulo-fenicios}

Avieno los sitúa junto a los mastienos, cilbicenos y tartesios junto al río Criso (Guadiaro) (v. 421) (Montenegro y otros 1989: 327; Lomas y otros 1980: 153). Apiano (Iber. 56) los denomina blastofenicios. Algunos autores expresan la identidad entre bástulos y los denominados bastetanos, mientras que otros autores los diferencian claramente (Plinio, III, 19) (Pastor y otros 1992). Estrabón es partidario de su identificación, situando a Calpe (Peñón de Gibraltar) en su territorio (III, 1, 7).

Ptolomeo los denomina (II, 4, 6) bástulo-púnicos, lo que parece indicar que en este territorio existían pueblos fenicios y cartagineses. El término de bástulo-fenicio o libio-fenicio haría alusión a la población colonial fenicia que se instaló en la costa sur peninsular, influyendo a la población indígena anterior.

Sus límites occidentales habría que situarlos a partir de Cádiz, desde donde se localizan los primeros asentamientos fenicios, siendo más difícil de caracterizar sus fronteras orientales. Las ciudades adjudicadas a este grupo por los textos jalonan toda la zona costera meridional hasta Villaricos (Almería), pero admitiendo la existencia del grupo mastieno habría que pensar que en la zona de Almería habría que ubicar muy probablemente al pueblo mastieno. Que los mastienos fueron un grupo distinto a estos bástulo-fenicios se advierte claramente en las fuentes, en especial en Avieno (v. 421) que los sitúa en proximidad pero como poblaciones diferentes. En este caso, esta posible confusión se debería al común proceso de integración de los grupos indígenas costeros con los pueblos fenicio-púnicos que haría difícil el apreciar la frontera entre ambos. Particularmente pensamos que pudo hallarse en las proximidades de Adra.

En cuanto a la posible confusión bástulo-bastetano, creemos que podría deberse a una posible expansión o infiltración de los grupos bastetanos en dirección suroeste como podría quedar de manifiesto por la presencia

3. Las citas correspondientes a Ptolomeo y al resto de autores clásicos que a lo largo de este trabajo mencionaremos han sido tomadas de Schulten (1939-59). 
de una escultura de diosa entronizada, así como de algunas cerámicas, adjudicables al pueblo bastetano, en la ciudad de Cádiz, en época ya avanzada (Escacena 1989: 453). La capitalidad de los bastetanos, Basti, en el interior de Granada, aboga por la diferenciación entre estos grupos y los denominados bástulos, localizados desde las costas de Cádiz.

\section{3. Mastienos}

Son mencionados por Avieno en su Ora Maritima. En uno de los pasajes los sitúa junto a los libiofenicios, cilbicenos y tartesios al este del río Criso (Guadiaro) (v. 421) (Pastor y otros 1992; Abad 1992). En otro pasaje señala a Mastia como la ciudad de los mastienos (situada entre el cabo de Gata y el de Palos). Se suele identificar con Cartagena (Murcia) (Montenegro y otros 1992: 319-322).

Hecateo de Mileto, extractado por Esteban de Bizancio (F.H.A.p. 186-187, 4-8) menciona a los mastienos como una tribu próxima a las Columnas de Hércules, señalando como ciudades suyas Mastia, Suel, Sexi (Almuñécar), Mainobora (Málaga) y Molibdana. Quizás aquí podamos ver un ejemplo de la aludida confusión entre el territorio bástulo-fenicio y el mastieno.

La última mención de los mastienos se la debemos a Polibio, que escribió en el s. III a. C. (III, 24, 1 y III, 33,9). Cita la ciudad de Mastia de Tarsis como límite occidental de la navegación romana en relación con el tratado romano-cartaginés del 348 a. C. La ubica frente al cabo Bello. Igualmente menciona a los mastienos como mercenarios hispanos trasladados a África por Aníbal.

Los mastienos, según lo que se desprende de los textos, ocuparían la zona oriental costera meridional. Sus límites parecen estar en Mastia y debieron extenderse por la zona litoral, siendo difícil precisar hasta dónde. Es probable que ocuparan la zona litoral oriental, Almería y Murcia, quedando la franja costera occidental ocupada por los bástulo-fenicios. El olvido que la historiografía posterior parece tener con este grupo puede deberse a su asimilación por otras poblaciones, probablemente cartagineses o bastetanos.

\section{4. Bastetanos}

Aunque algunos autores tienden a asimilar a este pueblo con el grupo bástulo, somos partidarios de diferenciarlos por las razones que ya hemos aludido.

Estrabón los cita en diversos pasajes (Abad 1992). En un primer momento dice que los bastetanos o bástulos están situados en la costa entre Calpe y Cartagena (III, 4, 1), mientras que en otro los sitúa en el interior, al sur de los celtíberos (III, 4, 12 y III, 4, 14), más o menos en el mismo lugar que los sitúa Ptolomeo (II, 6, 60), en la Oróspeda, la cordillera andaluza que va desde Cartagena a Málaga (Montenegro y otros 1989: 322-326).

Este último dato parece más acorde con los materiales arqueológicos señalados por Almagro y con la ubicación de la propia ciudad de Basti.

Los bastetanos debieron ocupar la región interior del sureste y quizás posteriormente se expandirían y ocuparían zonas del litoral, lo que podría explicar la confusión que recogen algunos textos.

\section{5. Mentesanos}

Pueblo éste quizás menos conocido, pero del que también se hacen eco los escritores clásicos (Montenegro y otros 1989: 322-326; Pastor y otros 1992: 122-124). 
Plinio nos dice (III, 19): "Los primeros son los bástulos, en la costa; tras ellos, yendo hacia el interior en el orden en que van enumerados siguen los mentesani, los oretani... y, junto al Tagus, los carpetani".

En otro pasaje Plinio comenta (III, 25): “ A Carthago concurren 65 pueblos... los mentesani conocidos también como oretani; los mentesani, apellidados bastuli; los oretani, cognominados germani..."

En este texto se denomina a unos mentesanos oretanos y a otros bástulos. Asimismo se diferencian dos etnias oretanas, los mentesanos oretanos y los oretanos germanos.

Mentesa es igualmente citada por Ptolomeo entre las ciudades oretanas (II, 6, 58). Otras ciudades mentesanas conocidas por las fuentes son Auringis (Jaén), Sucaelo (en el Cerro de las Cabezas, Fuente Tójar, al sureste de la provincia de Córdoba) y Tucci (Martos) (Montenegro y otros 1989: 325).

La mención de mentesanos, calificados como oretanos y en otros lugares como bastetanos ha llevado a la búsqueda de dos ciudades denominadas Mentesa, una supuestamente bastetana y otra oretana. Se ha ubicado la ciudad de Mentesa en La Guardia (Jaén) (Ruiz 1992: 116; Pastor y otros 1992: 124) por el hallazgo de una inscripción. Estos mentesanos serían los mismos a quienes Livio (XXVIII, 3) denomina maesesos, con su frontera en Orongis (Jaén) (Montenegro y otros 1989: 323). Se quiere entonces localizar otra ciudad Mentesa oretana que explique esta doble alusión. Pero quizás sería más lógico pensar que esta mención de grupos mentesanos oretanos y bastetanos se deba con toda probabilidad al hecho de estar el territorio mentesano a merced de diferentes poblaciones, a causa de la expansión de estos grupos y de la variabilidad de sus fronteras.

La Guardia es una de las ciudades en las que se han descubierto esculturas de leones, reutilizadas en cámaras funerarias, que supuestamente pertenecen al grupo vecino, es decir, a los bastetanos. Si La Guardia es la Mentesa a la que aluden las fuentes podría así explicarse esta extraña mención de los mentesanos como oretanos o bastetanos, atendiendo a la movilidad de las fronteras. Otro caso similar sería el de Toya, citada en algunos textos como oretana y en otros como bastetana (Montenegro y otros 1989: 336). Podría, por tanto, existir alguna marca fronteriza que haya podido estar en algunos momentos bajo el control bastetano u oretano, lo que explicaría esta dualidad.

En ese caso, si los mentesanos son grupos oretanos y si su capital, La Guardia, es una ciudad enmarcada dentro del área de los leones ¿podría corresponder el área de distribución de las esculturas de leones del período antiguo con la dispersión del grupo oretano? Algunas de las ciudades mencionadas como mentesanas se localizan precisamente en este sector.

\section{6. Oretanos}

La localización geográfica de los oretanos a través de las fuentes se presenta poco precisa e incluso contradictoria (Pastor y otros 1992).

Ptolomeo cita como ciudades oretanas: Al sur del Guadalquivir, Tuia (Toya, conocida por otros datos como bastetana) y Laecuris; al norte Salaria (Úbeda, Jaén) (Blázquez y García-Gelabert 1992; Montenegro y otros 1989: 336). Otras ciudades se hallan entre el Guadalquivir y el Guadiana, caso de Cástulo (Cazlona, Jaén), Oreto (probablemente Granátula de Calatrava o Alarcos, Ciudad Real), Aemiliana y Sisapo (Almadén, Ciudad Real) (Montenegro y otros 1992: 334-339; González-Conde 1992: 304).

Baecula (Bailén, Jaén) es citada por Polibio (X, 38, 7 y 11, 20) y Livio (XXVII, 18 y XXVIII, 13). Posiblemente sean también oretanas Amstorgis e Ilorci, relacionadas con la muerte de Escipión. Plinio sitúa claramente a la última en el Alto Guadalquivir (III, 9). Estrabón nombra a Cástulo y Oreto (III, 3, 2) como las grandes ciudades oretanas.

Estrabón comenta (III, 4, 14): “Tras los keltíberes, y en dirección Sur, siguen los pueblos que habitan la Oróspeda y las tierras que baña el Soúkron. Estos pueblos son los edetanoí, hasta Karchedón y los bastetanoí y oretanoí, hasta cerca de Málaka”. 
De esta cita se desprende una ubicación del pueblo oretano más meridional de lo que habitualmente se viene considerando.

Señala Estrabón (III, 4, 12): "El Baítis, que tiene sus fuentes en la Orospéda, atraviesa la Oretanía, fluyendo hacia la Baitiké".

En este fragmento la Oretania queda ubicada a ambas márgenes del curso del Guadalquivir.

También nos llega a través de Estrabón (III, 4, 2) "Partiendo de la región de Kálpe, cruza la Bastetanía y el país de los oretanoí una cordillera de densos bosques y corpulentos árboles que separa la zona costera del interior (la cordillara es la Orospéda)".

En otros fragmentos se considera a los oretanos vecinos de los turdetanos por el este (Estrabón III, 1, 6), o se dice que los oretanos son entre los vettones, carpetanos y lusitanos los más meridionales, llegando incluso hasta la costa, hasta el Estrecho de Gibraltar (Estrabón III, 3, 2).

Los datos expuestos ubican a los oretanos bordeando la cordillera subbética y a ambos lados del Guadalquivir, pudiendo coincidir arqueológicamente con el grupo antiguo de leones (fig. 1). En algunas ciudades nombradas como oretanas se han descubierto dichas esculturas, entre ellas Cástulo, la capital de los oretanos. Si es así, deberíamos preguntarnos: ¿qué relación existe entre los mentesanos y los oretanos? $\mathrm{Si}$ a los oretanos se les puede ubicar al sur del Guadalquivir ¿qué relación mantendrían con otras ciudades oretanas pero situadas al norte de este río, en el territorio comprendido entre el Guadalquivir y el Guadiana? Admitiendo que el área de dispersión de los leones en el Alto Guadalquivir es oretano ¿por qué contrasta con el vacío escultórico de la margen derecha del río, siendo el mismo grupo étnico.

Sobre estas cuestiones puede resultar significativo lo propuesto por Schulten (1972: 139 ss), quien llegó a proponer, basándose en la alusión de algunos textos, la presencia de unos oretanos germanos con centro en la ciudad epónima, distinguiendo entre estos oretanos y otros presumiblemente iberos (Montenegro y otros 1989: 338-339; Lomas y otros 1980: 153; González-Conde 1992: 302). Uno de los argumentos sería la mención de Plinio (III, 25): “Oretani qui et Germani cognominantur”, o la de Ptolomeo (II, 6, 58): "Oretum Germanorum"; mientras que Polibio recogería a los pretendidamente oretanos iberos (III, 33, 9), al mencionar a los tersitas, oretes iberos y olcades, como mercenarios hispanos que fueron trasladados por Aníbal a África antes del inicio de su campaña hacia Italia. Esta misma división de la etnia oretana quedaría recogida por Plinio (III, 25), quien al mismo tiempo que menciona a los oretanos germanos menciona a otros mentesanos oretanos.

Las conocidas capitalidades oretanas: Oreto y Cástulo podrían adquirir un sentido si se vincularan a esta división en dos áreas culturales dentro de la etnia oretana, Oreto, en torno a la cual pivotarían los oretanos germanos y Cástulo, capitalidad de los oretanos iberos. La arqueología podría corroborar esta división. Oreto se ubica en la zona de vacío escultórico (salvo su capital), mientras que Cástulo destaca por la presencia de esculturas monumentales, y como ya hemos expuesto la consideramos desde diversos puntos de vista vinculada al grupo situado en la margen izquierda del Guadalquivir, grupo que arqueológicamente está plenamente impregnado de la cultura material ibérica, al menos, desde el punto de vista cultural, aunque habría que analizar el origen étnico de estas poblaciones.

\section{EL ARMAMENTO}

Las poblaciones ibéricas mantuvieron como costumbre el colocar como ajuar en los enterramientos las armas de los guerreros. Las armas de hierro son uno de los elementos más abundantes en los ajuares de las necrópolis, apareciendo en todo tipo de tumbas. El repertorio que suele ser habitual está formado por: falcatas, espadas cortas triangulares, soliferrea, lanzas, asas de escudo, etc. 
El área turdetana parece, sin embargo, especialmente pobre en hallazgos. El único armamento localizado en este sector consiste en:

- Necrópolis del Cerro de las Balas (Écija). Es una necrópolis iberoromana. El rito funerario es de incineración en urna. Apareció algún armamento, consistente en puñales de antenas célticos o celtibéricos (Esther Núñez, com. oral; Núñez y Muñoz 1988).

- Tumba de Sevilla (Museo Arqueológico). Se halló un soliferreum (armamento celtibérico). Es de época romana (Escacena y Belén 1994).

- Necrópolis de El Hinojal (Arcos de la Frontera, Cádiz). Se encontró un umbo de escudo, dos hojas de espada y una punta de lanza. Es igualmente una necrópolis de fecha tardía.

- Almodóvar del Río (Córdoba): Se halló una falcata de hierro como ajuar de un enterramiento de incineración en urna. No se conoce bien su contexto (Escacena y Belén 1994).

- Camorra de Cabezuelas (Córdoba): Cerca de este poblado se halló una sepultura que constaba de una urna globular y armas de hierro, entre otros. Se le asigna una cronología del s. I a. C.

Los casos citados son totalmente insuficientes si se pretende identificar estos enterramientos con los ritos funerarios habitualmente practicados por toda la población de este área. Se trata además de vestigios de fecha muy avanzada, pertenecientes a momentos en los que se ha consolidado la dominación romana sobre los territorios de la Bética (Escacena y Belén 1994: 260). Algunos autores achacan este vacío de armamento al carácter pacífico de los turdetanos, transmitido por las fuentes, en las que se hace mención de los mercenarios celtibéricos utilizados por los turdetanos en sus conflictos bélicos, según relata Diodoro $(\mathrm{XXV}, 10)$. Esta presencia de celtíberos relatada por los autores clásicos podría guardar relación con el hecho de que la mayoría del armamento detectado en el Bajo Guadalquivir puede considerarse más celtibérico que ibérico. No obstante, extraña que cuantitativamente el armamento sea tan escaso, lo cual obliga a plantear las posibles causas que producen esta carencia de registros.

El problema se acentúa si atendemos a lo que ocurre en el Alto Guadalquivir, en el área de las esculturas. F. Quesada estudió el armamento ibérico y su distribución. Las falcatas abarcaban una amplia extensión geográfica, atribuibles en la zona sur y sureste a los grupos bastetanos y contestanos (Quesada 1992: 129-131). En cambio, otros sectores de la geografía peninsular no nos ofrecen muestras de este tipo de objetos. Pero de entre los vacíos existentes, uno de ellos es especialmente significativo: el del Alto Guadalquivir, la zona ocupada por las esculturas de leones.

Teresa Chapa, refiriéndose a las poblaciones que levantaron estos monumentos, comenta muy acertadamente: "La escultura funeraria es, por tanto, un reflejo de esta sociedad militarizada, con la suficiente complejidad como para mantener importantes talleres escultóricos". “...Este carácter bélico-mercantil que caracteriza a la sociedad ibera se refleja, por un lado, en el ajuar y situación de las tumbas, y por otro, en la temática de sus representaciones" (Chapa 1985: 264).

Luego, si admitimos el manifiesto carácter bélico de estas sociedades, debemos plantearnos forzosamente un interrogante: ¿Dónde está el armamento?

El límite de las falcatas hacia la zona del valle se atribuiría a la máxima expansión de los bastetanos, poblaciones que sí se asocian arqueológicamente con este armamento, pero el valle alto presenta una marcada ausencia, la misma que ofrecía el Bajo Guadalquivir.

Se ha interpretado la falta de constatación de ritos funerarios en el Bajo Guadalquivir como consecuencia de prácticas funerarias consistentes en arrojar los cadáveres al agua (Belén y Escacena 1992; Escacena 1992: 332-334), con la consiguiente desaparición del armamento empleado como ajuar (que en el caso de ser de hierro no podría recuperarse del agua).

Estas costumbres funerarias son propias de los pueblos indoeuropeos. Se ha atribuido un carácter indoeuropeo (Escacena 1992) a las poblaciones del suroeste peninsular que habría dejado huellas en la onomástica 
y en la toponimia, aunque sin determinar los mecanismos que han producido esta indoeuropeización. En ese caso, la ausencia de armamento en el Alto Guadalquivir podría obedecer a prácticas similares. No podemos aducir, como se ha hecho para los turdetanos, el carácter pacífico de estas gentes, puesto que la organización social reflejada a través de la plástica y de la iconografía guerrera en ella representada lo descarta. Por otro lado, la existencia de ciudades fortificadas está aludiendo al carácter bélico de estas gentes, lo que hasta ahora no queda bien atestiguado por la ausencia del armamento.

Una alternativa de explicación sería el admitir que estas poblaciones también arrojaban el armamento al agua, costumbre de procedencia indoeuropea, con lo cual, deberíamos pensar en el posible origen indoeuropeo de estas poblaciones que contrastaría con las costumbres de otros grupos ibéricos que depositan el armamento en sus necrópolis, como es el caso de los contestanos y bastetanos.

Es de destacar que la tónica general que reflejan las esculturas animalísticas es la falta casi absoluta de contexto arqueológico (Chapa 1985: 255-258; 1986: 231-237). La mayoría de las piezas conservadas han sido producto de hallazgos casuales y en el mejor de los casos, cuando se las localiza en necrópolis, obedecen a una reutilización en tiempos posteriores. Datos a tener en cuenta son los ofrecidos por la necrópolis del Cerrillo Blanco (Porcuna, Jaén) (González Navarrete 1987: 17-24), donde se recuperó un importante conjunto escultórico coincidiendo con un hiato en el uso funerario de la necrópolis, acontecido durante los s. VI y V a. C., lo que nos lleva a plantear ciertas dudas sobre la supuesta asociación originaria de estos monumentos a enterramientos, a pesar del sentido de "heroización" que poseen.

Por otro lado, las fuentes recogen datos que hacen pensar en un posible origen indoeuropeo de estas gentes ("Oretum Germanorum", "Oretanos, cognominados germanos"). Esta alusión podría tener correspondencia con las importantes influencias indoeuropeas que se han observado en la Oretania, tanto a nivel de cultura material como en aspectos lingüísticos (Blázquez y García-Gelabert 1992). La división en dos grupos, oretanos germanos y oretanos iberos, podría deberse a un proceso de aculturación progresivo, más acentuado en el caso de los oretanos ibéricos que les habría llevado a adoptar la cultura ibérica.

La presencia de armamento celtibérico, en fechas ya del s. IV a. C. en tumbas de Cástulo (Blanco 1965; Blázquez y García-Gelabert 1992: 51; Montenegro y otros 1989:241) es otro dato a retener sobre la posible procedencia indoeuropea de estas poblaciones. Más información aún podemos extraer de las representaciones artísticas.

\section{REPRESENTACIONES ARTÍSTICAS}

Es especialmente interesante el conjunto escultórico de Obulco (Porcuna, Jaén) (Quesada 1992: 92; González Navarrete 1987; Montenegro y otros 1989: 241-242). Los guerreros de Obulco del s. V llevan el armamento de la Meseta. Estrabón describe el armamento de los lusitanos (III, 3, 6), que según algunos autores tiene parentesco con el de los guerreros de Obulco (Montenegro y otros 1989: 241-242; Blanco 1987; Blázquez y García-Gelabert 1992). Su escudo es pequeño y cóncavo en su lado anterior. Lo llevan suspendido por delante con correas. Van armados también con puñal o cuchillo. La mayoría llevan coraza de lino y pocos cotas de malla y cascos de tres cimeras. Los infantes usan perneras y llevan varias jabalinas. Algunos se sirven de lanzas con puntas de bronce.

Los escudos de Obulco son convexos, de tres o cuatro discos superpuestos, cuelgan del cuello mediante correas y se sujetan por una abrazadera al centro. Los cascos son de dos tipos: uno de ellos se ajusta a la cabeza; lleva refuerzos metálicos con dos protuberancias acaracoladas a los lados, con profundos alveolos para alojar apéndices de forma desconocida, tal vez cuernos o penachos; va decorado con dos animales. A. Blanco (1987: 418) lo relaciona con la descripción de los cascos galos hecha por Diodoro $(\mathrm{V}, 30,2)$. 
En el relieve de Osuna perteneciente a un conjunto fechado a fines del s. III ó en el s. II a. C. (Quesada 1992: 100; Montenegro y otros 1989: 242) los guerreros llevan falcatas, caetras, escudos de la Tène y cascos con cimera. Otro relieve hallado en Sevilla procede de un conjunto próximo a Alhonoz. Aunque está muy mal conservado en él se aprecia una figura con falcata y escudo (Quesada 1992: 100).

Podríamos añadir a estos datos las monedas acuñadas en la ceca de la zona de Carmona (Sevilla), que emitió a mediados del s. II a. C., monedas en las que aparecen representadas las falcatas junto con la caetra (Quesada 1992: 113).

Tenemos atestiguada, a través de las manifestaciones artísticas, la existencia de un armamento que podríamos calificarlo como celtibérico en la zona del Valle del Guadalquivir. Este hecho guarda relación con el escaso armamento hasta ahora recuperado en la zona, de carácter celtibérico. Sin embargo, destaca que el registro arqueológico de este material siga siendo cuantitativamente escaso.

Los motivos recogidos tanto por las monedas como por las representaciones escultóricas asociadas a los monumentos funerarios reflejan los símbolos de esas comunidades, o mejor dicho, los símbolos que distinguen a las aristocracias locales. Los monumentos funerarios, o quizás sería mejor denominarlos monumentos conmemorativos, fueron levantados como recordatorio de los héroes. Las élites se hacían rodear de un carácter sacro que manifestarían a través de las representaciones. Se les heroificaba a su muerte (Quesada 1992: 92) y se escenificaba su paso al más allá al modo de un combate, llevado a cabo por esta casta de "guerreros" que se definía por su símbolo de poder: la "falcata".

Las falcatas aparecen en las monedas del Bajo Guadalquivir, en los relieves de Osuna, Alhonoz, en Obulco. Las élites rectoras se representan a sí mismas y dejan constancia de sus atributos de poder en representaciones figurativas. Por ello, el problema que se plantea es la ausencia de este tipo de armamento en este sector.

Según Quesada las evidencias materiales más antiguas para la falcata son por ahora de principios del s. IV a. C., y no antes. Sin embargo, admite un período anterior (finales del s. VI a. C.) para el que no se conocen necrópolis ibéricas en cuyos contextos puedan localizarse, pero que nos habrían sido transmitidas a través del conjunto escultórico de Porcuna (Quesada 1992: 138). Quesada se inclina por otorgar al armamento de Porcuna una fecha de principios del s. V a. C. Recogiendo palabras de este autor: "El que la ausencia de armas conocidas de este período (s. VI) y del s. V a. C. nos prive de conocer restos materiales de la falcata no es razón para negar su existencia si contamos con la evidencia positiva de Porcuna" (Quesada 1992: 139).

La ausencia del armamento en la zona del Alto Guadalquivir quedaría explicada si éste fuera arrojado al agua con motivo de prácticas funerarias. Este hecho y otros datos nos conducirían a admitir la posibilidad de que la aristocracia guerrera del Alto Guadalquivir fuese de origen indoeuropeo, teniendo presente toda la controversia y problemática que plantea la definición del concepto de "indoeuropeo". Esto podría relacionarse con la alusión sobre la presencia de mercenarios celtibéricos presentes en estas zonas recogida por los escritores clásicos. Serían gentes que paulatinamente habrían ido aculturándose, e incluso acabarían adoptando la lengua ibérica. Este hecho haría cuestionarnos el concepto de celtibérico que pudo variar según avanzara el proceso de aculturación.

Polibio escribía que el Guadalquivir y el Guadiana nacían en la Celtiberia y parece ser que este autor sabía lo que decía, puesto que comenta la distancia existente entre ambos ríos, cantidad que es aproximadamente correcta (Estrabón III, 2, 11).

\section{LINGÜÍSTICA}

El nombre de Ipolca (Obulco) posee el prefijo “ip-“(Untermann 1984) propio del mundo tartésico y el sufijo "olca" (Blázquez y García-Gelabert 1992: 50; Lomas y otros 1980: 55) reconocible como celta. En las monedas de Obulco están atestiguados nombres de magistrados en alfabeto indígena que parecen ser 
celtas (Blanco 1987: 405-408; Blázquez y García-Gelabert 1992: 46). Según U. Schmoll (1962), una serie de nombres obulconenses son todo menos ibéricos y atribuye los nombres de los magistrados que sí pueden considerarse como ibéricos a una más reciente ocupación por los íberos de territorios no ibéricos.

En opinión de A. Tovar, los oretanos son pueblos indoeuropeizados en su onomástica personal y toponimia. Este autor indica que en Cástulo se advierten huellas de lenguas indoeuropeas (Tovar 1985: 6, 8, 20). Podemos citar la presencia de antropónimos indoeuropeos en Cástulo. Se conoce a Cerdubelo (Blázquez y GarcíaGelabert 1992: 52; Montenegro y otros 1989: 339), al que se ha considerado un magistrado o persona importante de Cástulo, pues aconsejó su rendición a Roma en el año 206 a. C. Al comienzo de la conquista de Turdetania por los Bárquidas, Istolacio e Indortes, nombres típicamente celtas, eran los jefes de la lucha contra los cartagineses (Montenegro y otros 1989: 241).

Untermann (1985: 14-15) atribuye la expansión de la lengua ibérica por la zona meridional a un movimiento demográfico en sentido este-oeste, que llevaría a la superposición de capas lingüísticas y que tendría su principal evidencia en el desplazamiento del topónimo ibérico “ili’'. Se inclina a fechar este desplazamiento de poblaciones a partir del s. IV a. C. Belén y Escacena atribuyen esta iberización del territorio a un movimiento demográfico y cultural expansivo desde el sureste hacia Andalucía, más que a la herencia directa de lo tartésico (Belén y Escacena 1992: 82-83; Escacena 1992: 336).

Los datos recopilados nos inclinan a pensar en la posible relación de esta expansión con el grupo oretano ibérico o mentesano oretano del Alto Guadalquivir. Nombre éste de mentesano menos conocido, lo que resultaría una contradicción, dada la importancia del foco del Alto Guadalquivir. Este hecho quedaría explicado por las distintas denominaciones recibidas por un mismo grupo: oretanos, oretanos ibéricos o mentesanos. Grupos guerreros que muy bien pudieran ser indoeuropeos aculturados, los cuales habrían llegado a adoptar la lengua ibérica, y que en fechas avanzadas lograrían infiltrarse en territorio turdetano. Esto explicaría las referencias que se hace en los textos sobre oretanos germanos y asimismo podría aclarar la procedencia de los mercenarios celtibéricos en tierras turdetanas, atestiguados por las fuentes y por el armamento celtibérico localizado en esta zona.

Nos queda planteada la duda de si la dispersión de la estatuaria de leones del período reciente (fig. 2), atribuida a las legiones romanas, no guarda ninguna relación con el sustrato indígena anterior. Podemos atestiguar a través de las representaciones figurativas de Obulco y de Osuna, que estos monumentos funerarios mantienen una relación directa con grupos guerreros celtibéricos. Por ello, no sabemos hasta qué punto pudo incidir el fenómeno de la romanización en estos grupos, y si quizás la distribución que muestra el mapa reciente de estatuaria de leones (fig. 2) puede ser indicativa de algún proceso de aculturación o asimilación por parte de los grupos guerreros del Alto Guadalquivir, en relación directa con la expansión de la escultura.

\section{LA CERÁMICA}

La cerámica podría, asimismo, ser portadora de información referente al supuesto origen indoeuropeo de los grupos asentados en el Alto Guadalquivir.

Diversos autores han indicado la filiación indoeuropea de elementos localizados entre los pueblos oretanos de la Meseta (Mena y Ruiz 1987; Blázquez y García-Gelabert 1992). La proyección de los pueblos de la Meseta sobre Turdetania se ha atribuido a la presencia de los mercenarios en estas tierras. En momentos del Bronce Final el elemento indoeuropeo podría identificarse en Cástulo, según diversos autores, por la presencia de cerámicas grafitadas e incisas. A estas cerámicas se les ha atribuido un origen septentrional, lusitano y celtibérico (Blázquez y Valiente 1985). 
Lo que sí es cierto es que en la Baja Andalucía y región costera de la misma a partir de fines del s. VIa.C. se produce un declive progresivo de la cultura tartésica. En Huelva las importaciones de cerámica griega desaparecen prácticamente a fines del s. VI, hecho que parece estar en relación con la decadencia de los focos mineros occidentales y su sustitución por los de Sierra Morena. Sería éste el momento en que este sector deja de depender políticamente de Tartessos, surgiendo como foco autónomo, momento que habría que paralelizar con la aparición del fenómeno de la estatuaria monumental.

\section{CONCLUSIONES}

Las representaciones artísticas nos han dejado constancia de la existencia de una clase social guerrera, élite a la que estaban destinados estos monumentos, cuyas evidencias apenas han sido detectadas en el registro arqueológico en el Alto y Bajo Guadalquivir. La causa de esta aparente anomalía podría residir en la particularidad de sus costumbres funerarias.

El mundo funerario nos muestra un confuso panorama en el que es difícil deslindar cada una de sus partes. Es una tendencia inevitable el tratar de globalizar los rituales funerarios, extrapolando una serie de evidencias arqueológicas a todo un mosaico de pueblos. Un punto de partida obligado en la investigación funeraria debería ser la individualización y adscripción de rituales funerarios diferenciados a etnias determinadas, a períodos temporales concretos e incluso a grupos sociales específicos. En la interpretación del registro funerario deberíamos tener siempre presente los cambios acaecidos a lo largo del tiempo, según se hayan ido desarrollando procesos de aculturación, la movilidad y expansión de grupos por territorios de otras comunidades que dejarían su huella en el registro funerario, la coexistencia pacífica en un mismo territorio de etnias diferentes o la diversidad ritual existente en el seno de una misma sociedad, según criterios de rango.

Desde este enfoque no vemos del todo claro el que los monumentos funerarios y la estatuaria adscrita a ellos deban ser asociados en todo momento y lugar a enterramientos, sobre todo tras observar que la cronología de alguno de ellos coincide con la ausencia de registros funerarios coetáneos, así como su mayoritaria asociación con enterramientos en momentos posteriores en los que son reutilizados. La investigación arqueológica no puede dar una respuesta cierta a este problema por el momento.

Las diferentes respuestas culturales observables en el mapa nos han permitido extraer algunas conclusiones en torno a la identificación de las etnias meridionales peninsulares, sobre las que proponemos finalmente el siguiente esquema identificativo (fig. 7):

- Mentesanos/oretanos ibéricos. Escultura de leones antiguos y toros.

- Oretanos germanos. Ausencia de estatuaria monumental zoomorfa.

- Turdetanos. Leones del Bajo Guadalquivir (período reciente).

- Túrdulos. Ausencia de estatuaria monumental zoomorfa.

- Bastetanos. Cámaras funerarias, diosas entronizadas, falcatas.

- Bástulo-fenicios. Presencia colonial fenicia, ausencia de estatuaria monumental.

- Mastienos. Presencia colonial fenicia, ausencia de estatuaria monumental zoomorfa.

- Contestanos. Leones, toros, animales fantásticos, falcatas (fig. 4).

— Púnicos. Esculturas de caballos en época reciente? (fig. 6).

Además de estos elementos hemos de añadir la hasta ahora aparente ausencia de armamento en determinados sectores de la geografía, en especial falcatas, entre los pueblos del Bajo y Alto Guadalquivir, turdetanos y mentesanos oretanos. Ausencia que se aprecia en determinadas fechas y que contrasta con su registro en representaciones artísticas. 
Así pues, en resumen, hemos intentado correlacionar la información proporcionada por los textos antiguos con la distribución de ciertos elementos arqueológicos que creemos de especial relevancia para tratar de identificar a las diferentes poblaciones. Grupos que tratan de plasmar sus rasgos diferenciadores sobre todo a través de elementos que guardan estrecha relación con el campo de sus creencias. Por ello, hemos considerado a la estatuaria zoomorfa uno de los elementos más adecuados para este cometido. El estudio de los textos escritos en conjunción con otros criterios arqueológicos tienen la última palabra sobre su posible o no adscripción a las poblaciones mencionadas.

\section{BIBLIOGRAFÍA}

ABAD, L. (1992): "La cultura del área suroriental de la Península Ibérica", Complutum 2-3: 151-166.

ALMAGRO-GORBEA, M. (1982): "Tumbas de cámara y cajas funerarias ibéricas. Su interpretación sociocultural y la delimitación del área cultural ibérica de los bastetanos", Homenaje a Conchita Fernández Chicarro: $249-257$.

ARTEAGA, O. (1977): "Las cuestiones orientalizantes en el marco protohistórico peninsular", Cuadernos de Prehistoria de la Universidad de Granada 2: 301-320.

BELÉN, M. y ESCACENA, J.L. (1992): "Las comunidades prerromanas de Andalucía occidental", Complutum 2-3: 65-88.

BLANCO, A. (1965): "El ajuar de una tumba de Cástulo", Oretania 19. (1987): "Las esculturas de Porcuna I. Estatuas de guerreros", Boletín de la Real Academia de Historia 184: $405-446$.

BLÁZQUEZ, J.M. y VALIENTE, J. (1985): "El santuario preibérico de Cástulo. Relaciones entre la Meseta y Andalucía en la protohistoria”, Actas del III Coloquio sobre lenguas y culturas paleohispánicas: 179-200. Salamanca, Edic. Universidad.

BLÁZQUEZ, J.M. y GARCÍA-GELABERT, M.P. (1992): "Relaciones entre la Meseta y Oretania", Complutum 2-3: 45-55.

BURILLO, F. (1993): “Aproximación a la arqueología de los celtíberos”, en Los celtas: Hispania y Europa: 223-253. Madrid, Universidad Complutense.

CHAPA, T. (1980): La escultura ibérica zoomorfa. Tesis Doctoral. Madrid. (1985): La escultura ibérica zoomorfa. Madrid.

(1986): Los influjos griegos en la escultura zoomorfa ibérica. Madrid, Iberia Graeca. Serie arqueológica $n^{\circ}$ 2. C.S.I.C.

ESCACENA, J.L. (1989): "Los Turdetanos o la recuperación de la identidad perdida", en Tartessos. Arqueología Protohistórica del Bajo Guadalquivir: 433-476. Sabadell, Ed. Ausa. (1992): "Indicadores étnicos en la Andalucía prerromana", Spal 1: 321-344.

ESCACENA, J.L y BELÉN, M. (1994): "Sobre las necrópolis turdetanas", Homenaje al Profesor Presedo. Universidad Sevilla: 237-265.

GARCÍA Y BELLIDO, A. (1987): La España del s. Id. C. Según P. Mela y C. Plinio. Madrid, Espasa-Calpe. (1993): España y los españoles hace dos mil años. Según la Geografía de Strábon. Madrid, Espasa-Calpe.

GONZÁLEZ-CONDE, M.P. (1992): "Los pueblos prerromanos de la Meseta Sur", Complutum 2-3.

GONZÁLEZ NAVARRETE, J.A. (1987): Escultura ibérica del Cerrillo Blanco. Porcuna, Jaén. Jaén, Diputación provincial, Instituto de Cultura.

LOMAS, F.J. y otros (1980): Historia de España Antigua I. Protohistoria. Madrid. 
MENA, P. y RUIZ, A. (1987): "Elementos celtas del oppidum de Alarcos (Ciudad Real)", XVIII Congreso Nacional de Arqueología: 635-645.

MONTENEGRO, A. y otros (1989): Historia de España 2. Colonizaciones y pueblos prerromanos. Madrid. NÚÑEZ, E. y MUÑOZ, J. (1988): "Excavaciones en la Necrópolis del Cerro de las Balas, Écija", Anuario Arqueológico de Andalucía, T. III: 429-433.

PASTOR, M. y otros (1992): "Paleoetnología de Andalucía oriental (Etnogeografía)", Complutum 2-3: 119-136.

QUESADA, F. (1992): La falcata ibérica. Alicante, I.C. Juan Gil Albert.

RODRÍGUEZ DÍAZ, A. (1993): "Sobre la periferia turdetana y la configuración diversa de la Beturia prerromana. Célticos y túrdulos en el Guadiana medio", Spal 2: 243-267.

RUIZ, A. (1992): "Etnogénesis de Andalucía oriental”, Complutum 2-3: 101-118.

SCHMOLL, U. (1962): "Zur Entzifferung der südhispanischen Schrift", Madrider Mitteilungen 3.

SCHULTEN, A. (1935-59): Fontes Hispaniae Antiquae. Barcelona, Universidad. (1972): Tartessos. Madrid.

TOVAR, A. (1985): "Lenguas y pueblos de la Hispania Antigua", IV Coloquio Internacional de lenguas y culturas paleohispánicas: 18 y ss. Vitoria.

UNTERMANN, J. (1984): “La lengua ibérica”, Varia III: 249-272.

(1985): "Lenguas y unidades políticas del suroeste hispánico en época prerromana”, De Tartessos de Cervantes: 1-40. Köln. 


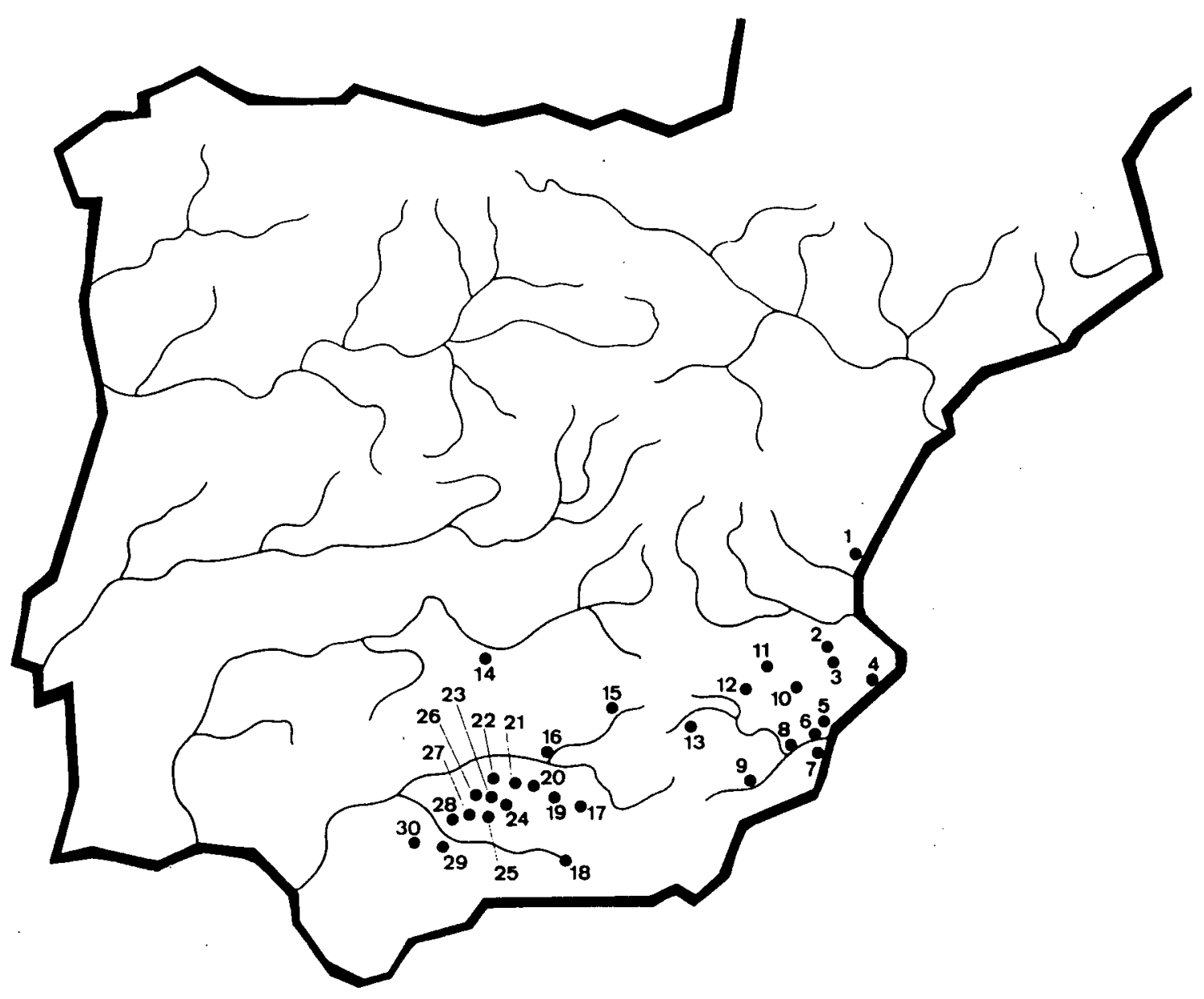

Figura 1: Escultura de leones ibéricos. Grupo antiguo, s. VI-IV a.C. (T. Chapa).
1. Sagunto
11. Pozo Moro-Aldea de la Cueva
21. Porcuna
2. Corral de Saus
12. Liétor
22. Manga Granada
3. Bocairente
4. Tossal de la Cala
13. El Macalón
23. Castro del Río
5. Elche-La Alcudia
14. Alarcos
24. Baena
6. La Escuera
15. Castillar de Santiesteban
25. Nueva Carteya
7. El Molar
16. Cástulo
26. Fernán Núñez
8. Cabecico del Tesoro
17. Huelma
27. La Rambla
9. Coy
18. Trasmulas
28. Santaella
19. La Guardia
29. Herrera
10. El Zaricejo (Villena)
20. Villadonpardo
30. Marchena 


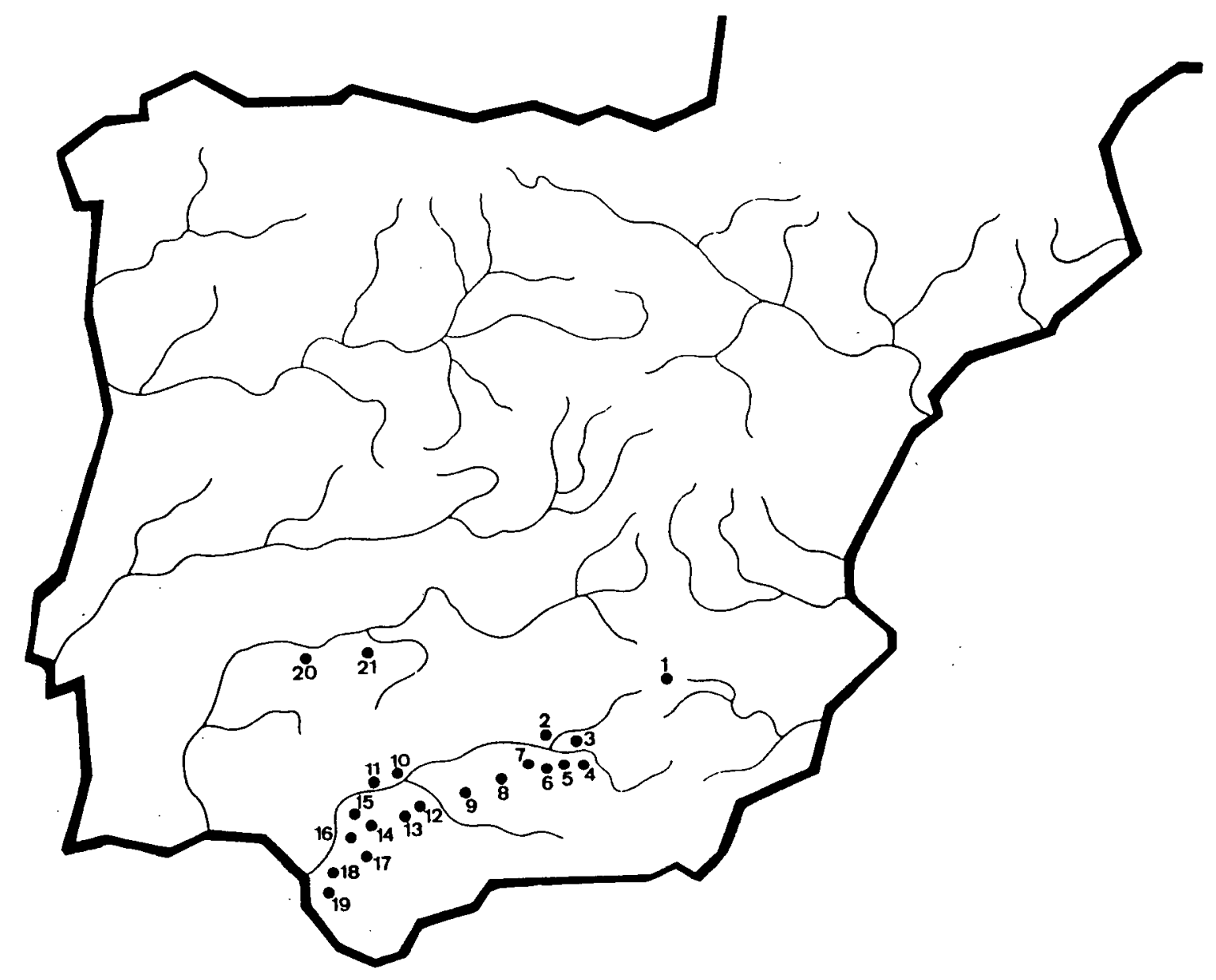

Figura 2: Escultura de leones ibéricos. Grupo reciente, s. III a.C. (T. Chapa).

1. Bienservida

2. Cástulo

3. Úbeda la Vieja

4. Albánchez de Úbeda

5. Cerro Alcalá

6. Torres

7. Torredonjimeno

8. Baena

9. Santaella

10. Peñaflor

11. Alcolea del Río

\section{Estepa}

13. Osuna

14. El Coronil

15. Utrera

16. Las Cabezas de San Juan

17. Bornos

18. Mesas de Asta

19. Jerez de la Frontera

20. Mérida

21. Magacela 


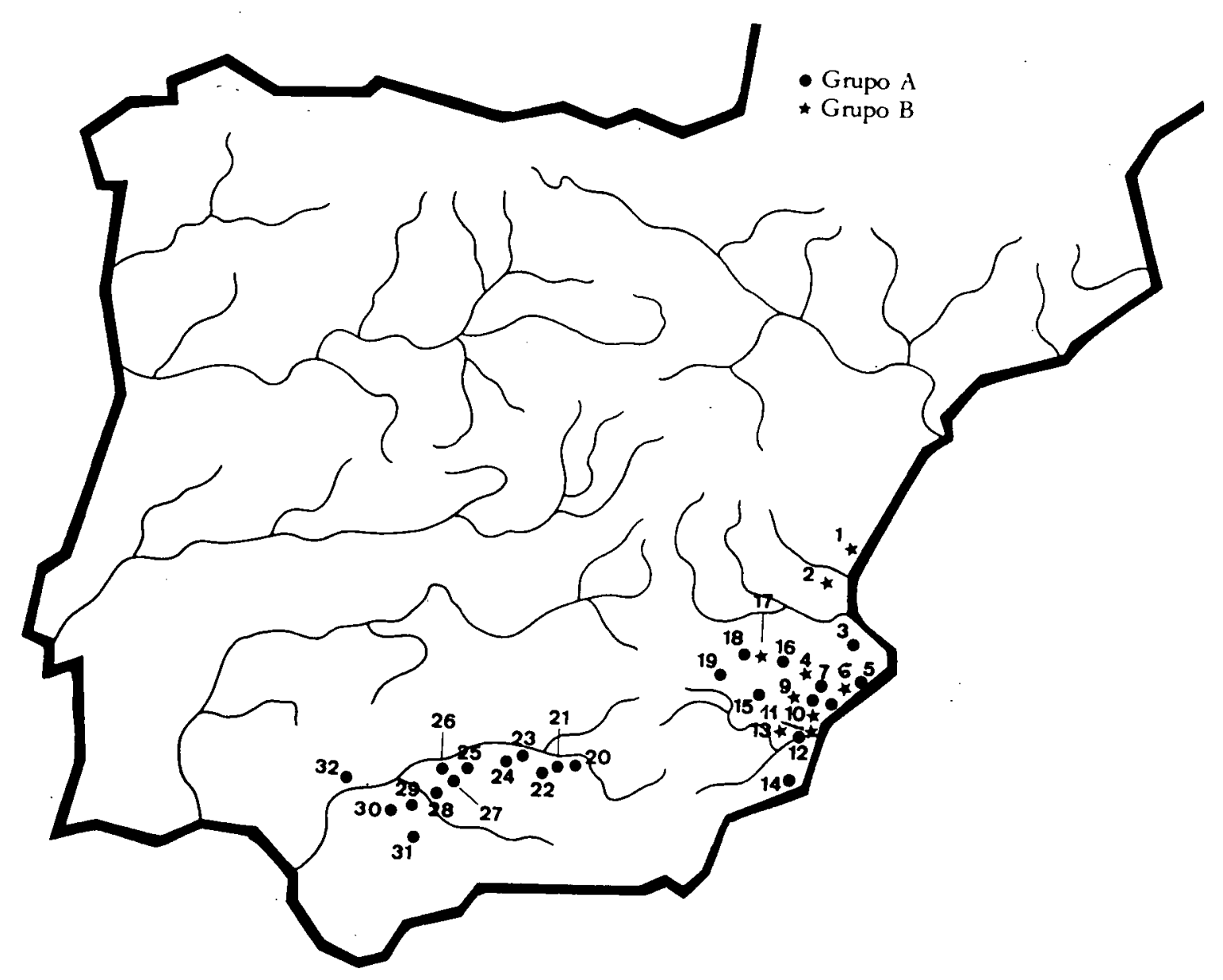

Figura 3: Escultura en piedra de toros (T. Chapa).

1. Sagunto

2. La Carencia (Turis)

3. Balones

4. Sax

5. Tossal de la Cala de Benidorm

6. Villajoyosa

7. Agost

8. La Albufereta

9. Monforte del Cid

10. Elche

11. El Molar (Guardamar)
12. Cabezo Lucero

13. Redován

14. Los Nietos

15. Coimbra

16. Caudete

17. Cerro de los Santos

18. Llano de la Consolación

19. Hoya de Santa Ana

20. Cortijo del Álamo

21. Cerro Alcalá

22. La Guardia
23. Arjona

24. Porcuna

25. Espejo

26. Montemayor

27. La Victoria

28. Santaella

29. Écija

30. Fuente de Andalucía

31. Osuna

32. Alcalá del Río 


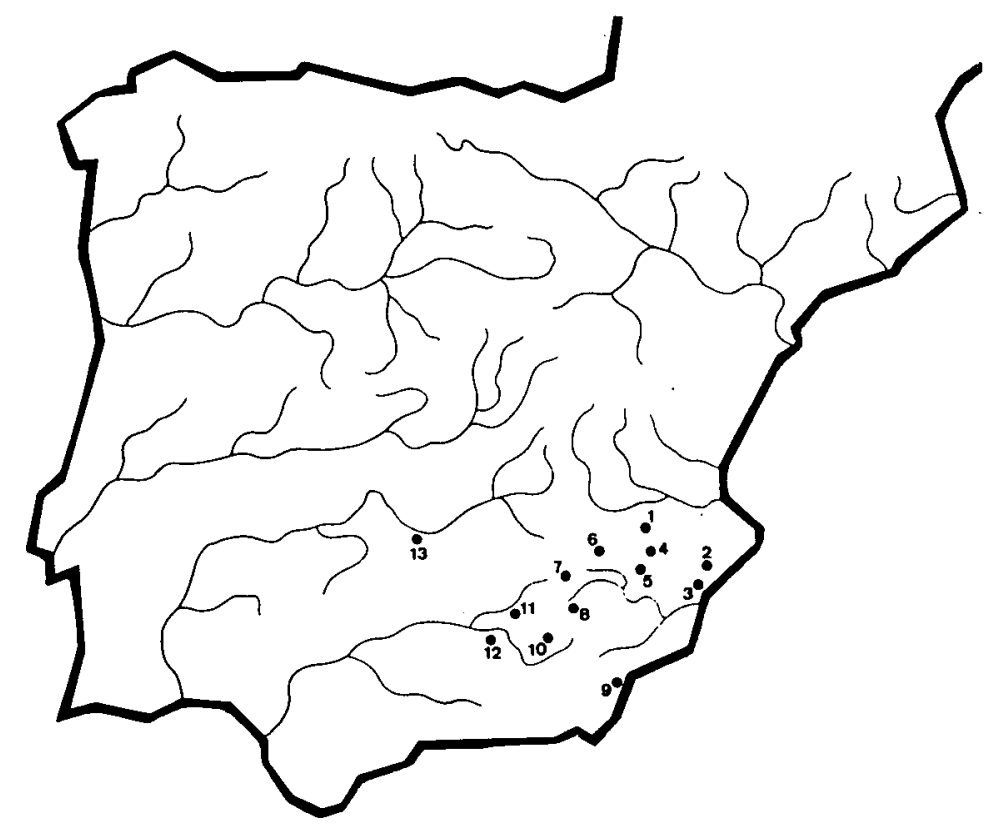

1. Higueruela

2. Agost

3. Elche

4. Llano de la Consolación

5. Ontur

6. El Salobral

7. Bogarra

8. El Macalón

9. Villaricos

10. Galera

11. Santo Tomé

12. Jódar

13. Alarcos

a Esfingies

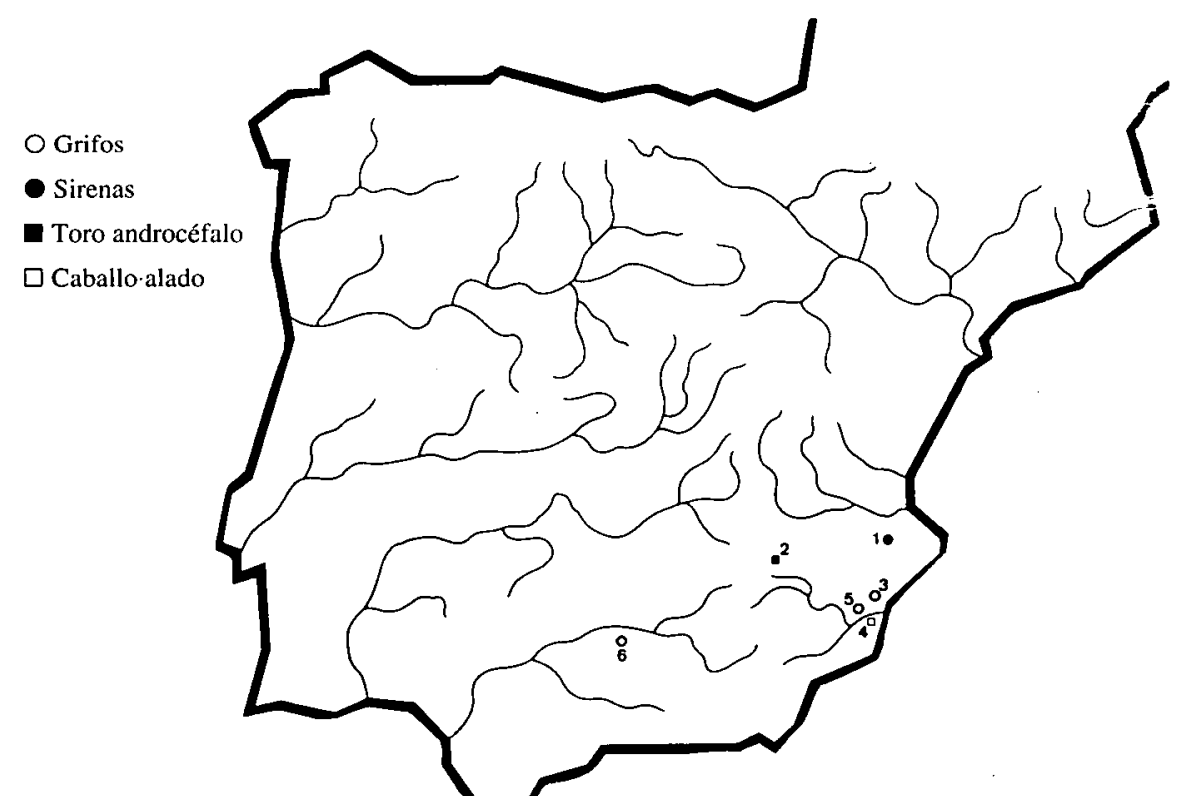

1. Corral de Saus

2. Bazalote

3. Elche

4. Benezújar

5. Redován

6. Porcuna

b. Otros animales fantásticos

Figura 4: Escultura en piedra de animales fantásticos (T. Chapa). 


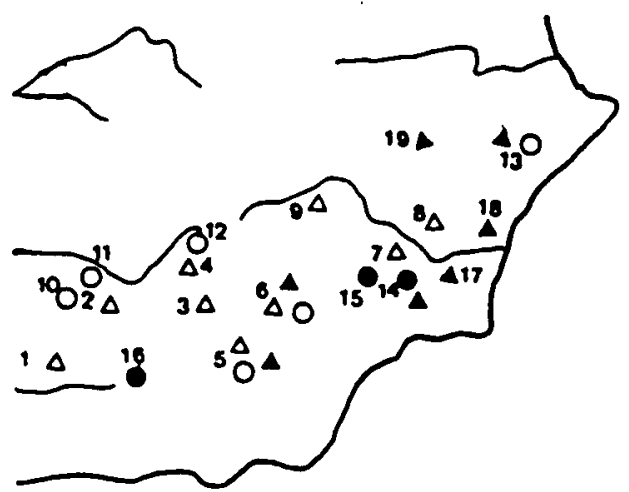

\author{
$\triangle$ Cámaras ibéricas \\ $\bigcirc$ Larnakes \\ Santuarios con caballos \\ A Diosas entronizadas
}

Área cultural bastetana a comienzos del s. IV a.C.

1. Almedinilla (Córdoba). - 2. La Guardia (Jaén). - 3. Castellones de Ceal (Jaén). -4. Toya (Jaén). - 5. Baza(Granada). 6. Galera (Granada). - 7. Archena (Murcia). - 8. Castillejo de los Baños (Murcia). - 9. Camarillas (Albacete). 10. Torredonjimeno (Jaén). - 11. Villagordo (Jaén). - 12. Peal del Becerro (Jaén). - 13 Alcoy (Alicante). 14. El Cigarralejo (Murcia). - 15. El Recueesto (Murcia). - 16. Pinos Puente (Granada). - 17. Verdolay (Murcia). 18. La Alcudia (Alicante). 19. Llano de la Consolación (Albacete).

Figura 5: Área Bastetana.

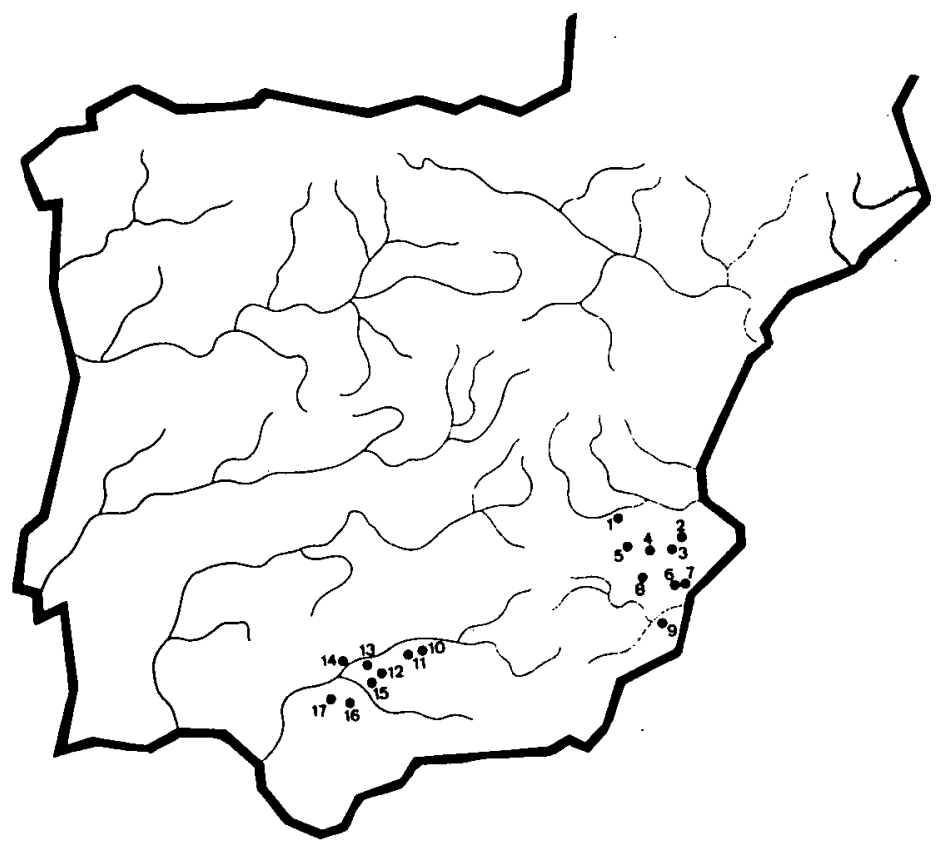

1. Casas de Juan Núñez

2. Corral de Saus

3. Fuente de la Higuera

4. Llano de la Consolación

5. Pozo Moro

6. Elche

7. La Alcudia

8. Jumilla

9. Cabecico del Tesoro

10. Arjona

11. Porcuna

12. Ategua

13. Córdoba

14. Almodóvar del Río

15. La Rambla

16. Osuna

17. Marchena

Figura 6: Escultura de caballos en piedra (T. Chapa). 


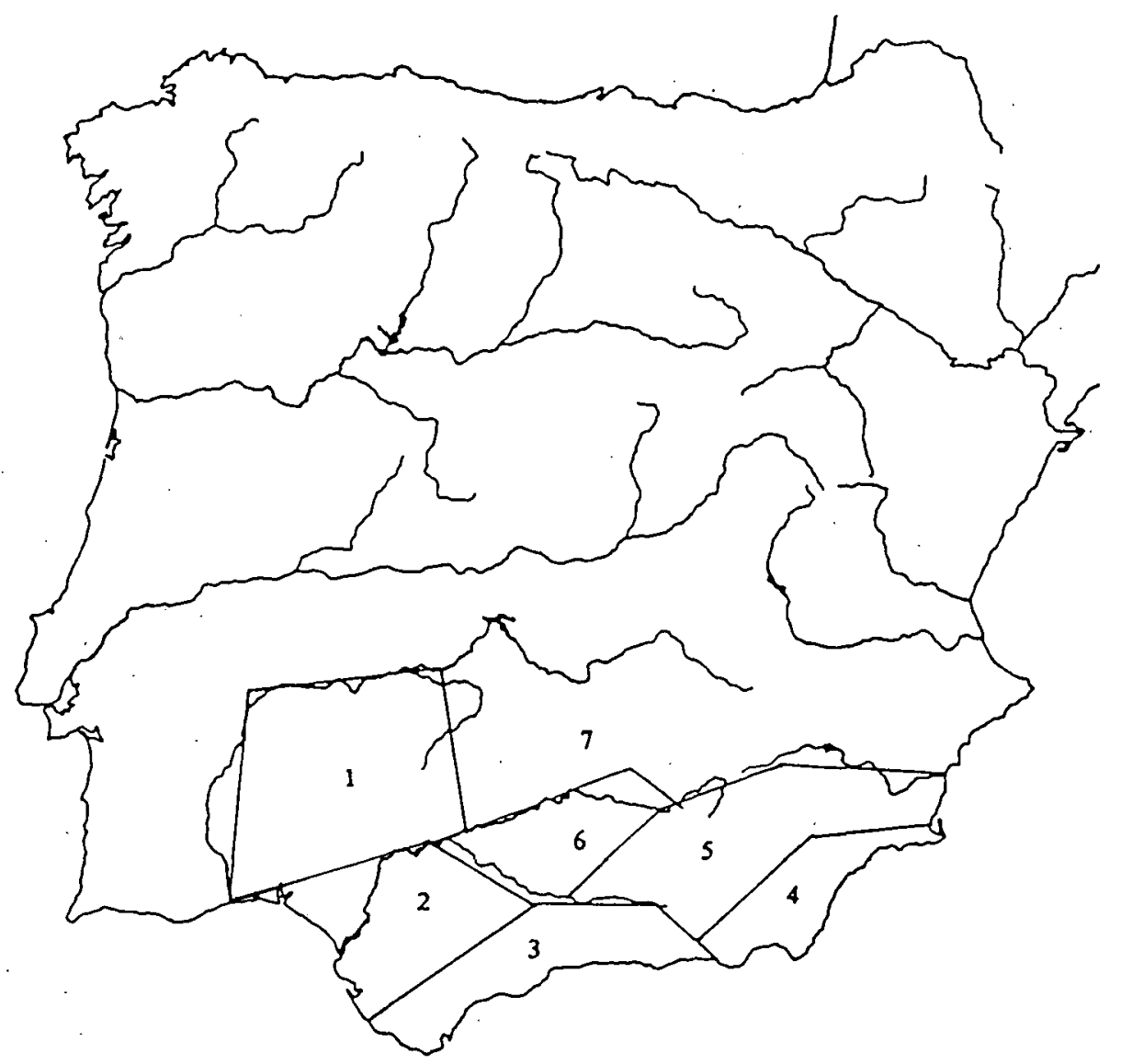

1. Túrdulos

Figura 7: Dispersión de las etnias prerromanas:

2. Turdetanos

3. Bástulos

4. Mastienos

5. Bastetanos

6. Oretanos (Mentesanos)

7. Oretanos Germanos 